\title{
Telemedicine for Delivery of Care in Frontotemporal Lobar Degeneration During COVID-19 Pandemic: Results from Southern Italy
}

\author{
Rosa Capozzo $^{\mathrm{a}, 1, *}$, Stefano Zoccolella ${ }^{\mathrm{b}, 1}$, Maria Elisa Frisullo ${ }^{\mathrm{a}}$, Roberta Barone ${ }^{\mathrm{a}}$, Maria Teresa \\ Dell' Abate $^{\mathrm{a}}$, Maria Rosaria Barulli ${ }^{\mathrm{a}}$, Marco Musio ${ }^{\mathrm{a}}$, Miriam Accogli ${ }^{\mathrm{a}}$ and Giancarlo Logroscino ${ }^{\mathrm{a}, \mathrm{c}}$ \\ ${ }^{a}$ Center for Neurodegenerative Disease and The Aging Brain at the Hospital Pia Fondazione \\ "Card. G. Panico"/University of Bari, Tricase, Italy \\ b ASL Bari, San Paolo Hospital, Neurology Unit, Bari, Italy \\ ${ }^{\mathrm{c}}$ Department of Basic Medicine, Neuroscience and Sense Organs, University of Bari “Aldo Moro”, Bari, Italy
}

\begin{abstract}
.
Background: The COVID-19 pandemic is changing clinical practice in neurology, after the governments decided the introduction of social distancing and interruption of medical non-emergency services in many countries. Teleneurology is an effective tool for the remote evaluation of patients but its adoption for frontotemporal lobar dementia (FTD) is in a preliminary stage. Objective: We evaluated multidisciplinary assessment of patients with FTD using telehealth during the COVID-19 pandemic. Methods: All patients received a diagnosis of FTD during 2018-2019 according to international criteria. A structured questionnaire and Clinical Dementia Rating Scale (CDR)-FTD were used by the neurologist with patients and/or caregivers. Index symptoms of COVID-19 infection were searched.

Results: Twenty-eight clinical interviews were completed with caregivers and four with both patients/caregivers. Most patients and caregivers were satisfied with the neurological interview and expressed their willingness to continue to be included in remote evaluation programs (90\%). Fifty percent of patients experienced significant worsening of clinical picture and quality of life since the start of social distancing. The CDR-FTD scale revealed a significant worsening of behavior $(p=0.01)$ and language functions $(p=0.009)$, compared to the last in-person evaluation at the center. One patient presented index symptoms of COVID-19 infection and was confirmed to be positive for COVID-19 with pharyngeal swab.

Conclusion: The study was conducted in Italy, one of the countries hit particularly hard by the COVID-19 pandemic, with interruption of all non-emergency medical services. Our study indicates that telemedicine is a valid tool to triage patients with FTD to increase practice outreach and efficiency.
\end{abstract}

Keywords: COVID-19, frontotemporal lobar dementia, multidisciplinary care, pandemic, quality life, telemedicine

\footnotetext{
${ }^{1}$ These authors contributed equally to this work.

*Correspondence to: Dr. Rosa Capozzo, Center for Neurodegenerative Disease and The Aging Brain at the Hospital Pia Fondazione "Card. G. Panico"/University of Bari, Tricase, Italy. Tel.: +39 0833773909; Fax: +39 08331830670; E-mail: rosa80capozzo@gmail.com.
}

\section{INTRODUCTION}

The 2019 coronavirus disease (COVID-19) outbreak has important implications for clinical care in Alzheimer's disease (AD) and frontotemporal lobar dementia (FTD). Many countries have implemented social distancing measures, such as quarantines 
within urban areas, prohibition of travel to and from certain countries, and suspension of broad range of activities, involving large numbers of people such as outpatients visits in public and private hospitals. All these decisions were aimed to limit the risk of COVID-19 infection.

Government containment maneuvers to reduce infections included the ban of all non-urgent clinical activities, thus limiting the access to hospitals, with significant discomfort for older people affected by chronic conditions. Not unexpectedly, such population segments, with high comorbidities and being particularly frail, have the highest mortality rate from COVID-19 [1]. FTD is an umbrella term encompassing a wide spectrum of clinical pictures characterized by progressive changes in behavior, personality, and/or language functions associated with degeneration of the frontal and temporal lobes [2-4]. Several clinical FTD variants have been described. The behavioral variant of FTD (bvFTD) and primary progressive aphasia (PPA) represent the most frequently recognized clinical syndromes, both in tertiary centers $[5,6]$ and in population-based settings [7]. Progressive supranuclear palsy (PSP) and corticobasal degeneration syndrome (CBD), and others which are considered to be part of the spectrum of tauopathies, have been shown to overlap both clinically and neuropathologically, and are considered under the same label of the FTD spectrum [8]. FTD also often overlaps with amyotrophic lateral sclerosis (ALS), with symptoms of FTD occurring in $15 \%-41 \%$ of patients with ALS and features of ALS occurring in $15 \%$ of FTD patients [9, 10]. Multiple system atrophy (MSA) may also present clinically and pathologically as an FTD [11]. Moreover, patients with FTD represent a segment that could be particularly affected by both the epidemic and the rules to reduce its transmission due to the specificity of FTD clinical features; patients have special difficulties in understanding changes in the surrounding environment and social rules [12].

It is well recognized that people with FTD benefit from multidisciplinary care in terms of survival and quality of life $[13,14]$. However, access to multidisciplinary clinics may be difficult for patients with FTD due to distance from the nearest tertiary referral center and costs of travel [15]. Patients with FTD have been particularly limited by the new rules during the COVID-19 epidemic. Moreover, in our country, a significant proportion of patients with dementia live in medically served residencies with high incidence of COVID-19 infections and an extraordinary high mortality [16].

Telehealth is a rapidly progressing field that is constantly exploring patient care with the support of multiple applications and services including remote videoconferencing, e-mail, apps, and other forms of technology. Teleneurology is an effective tool for the rapid evaluation of patients in remote locations [17] with a well-established use in acute stroke $[18,19]$ and epilepsy [20, 21] and more recently in neurodegenerative disorders, such as Parkinson's disease [22] and dementias [23-27]. Recent studies supported the use of telemedicine in cognitive rehabilitation in mild cognitive impairment, AD, and FTD [28].

Telehealth in the current COVID-19 pandemic has become the primary way to deliver care, especially as means of reducing the risk of cross-contamination caused by close contact [24]. Telemedicine approach in the era of COVID-19 has been used for monitoring of persons potentially affected by the virus $[1$, 24], but to date, no study on FTD is available. A recent editorial of the Alzheimer Association Society and other similar advocacy groups encouraged novel public health initiatives, including telehealth, from countries with large or growing populations with dementia in order to protect these vulnerable patients and their caregivers during the COVID-19 outbreak [29].

The aim of our study was to evaluate whether the assessment of patients with FTD using telemedicine is feasible and acceptable to patients and caregivers in the era of the COVID-19 pandemic.

\section{METHODS}

All study subjects were patients receiving multidisciplinary care at the Center for Neurodegenerative Disease and The Aging Brain of the University of Bari at the Hospital "Card. G. Panico" Tricase (Lecce). Subjects were enrolled within the "SLAP-Dem Study", a population-based study on rare neurodegenerative disease that was approved by the Ethics Committee for Medical Research at ASL Lecce on 25 May 2017. Both patients and their caregivers provided their informed consent verbally [Italian Guarantor for the protection of personal data has provided that for treatments for "treatment purposes" it is not necessary to acquire the patient's consent (Measures Registries n. 55, 7 March 2019)]. Patients with a diagnosis of bvFTD [30] and PPA [31], also overlapping with PSP [32] or other syn- 
dromes such as CBD, MSA, and ALS, according to the respective international criteria [33-35], were selected and contacted for the study. In particular, bvFTD and PPA plus Parkinsonism are defined as the presence of extrapyramidal signs not sufficient to meet diagnostic criteria for PSP, CBD, and MSA. All patients received a diagnosis in 2018 and 2019 after a complete clinical and paraclinical assessment and had at least one access for follow-up after the baseline visit at the Center during the year 2019; new cases with diagnosis after their first visit in the Center still pending or patients not referring to the Center in the last year were not included as it was assumed that they/we would not have a basis for comparison of their previous care. Patients were included regardless of disease severity and distance from the clinic.

The telemedicine approach (tele/cell-phone) from the clinic to patient's home was performed by the interaction of the neurologist with the patient (if it was possible) or the caregiver (defined as the person dedicated to the patient's care for at least 8-10 hours a day). The telemedicine assessment in this study was based on a structured questionnaire designed to collect demographics and clinical information [diagnosis, onset of disease, clinical status and changes since last visit in the following domains: cognition, behavior and personality, language, sleep disturbances, nutritional status, swallowing capacity, respiratory function, access to rehabilitation and speech therapy, pharmacological therapy] with the aim to identify significant changes or problems since the last multidisciplinary evaluation (see Supplementary Material). Disease progression was evaluated using the Clinical Dementia Rating Scale-FrontoTemporal Dementia (CDR-FTD) considering both SoB (sum of boxes) and the Behavior and Language items [36]. Results obtained during the teleconsultation were compared with those of the last in person evaluation at the center. We also assessed the distress induced on caregivers in the last period by the COVID-19 pandemic and subsequent governmental rules. The global caregivers' distress was evaluated on a Likert scale from 0 (none) to 5 (severe) with the caregiver distress question of the Neuropsychiatric Inventory [37].

The questionnaire also included information concerning possible signs/symptoms of COVID-19 infection in patients and/or caregivers/family. One week after the teleconsultation, a survey was administered via email or via WhatsApp to the patient or caregiver to ask participants about their opinion of the telemedicine interview.

\section{RESULTS}

Data were collected during the COVID-19 emergency from the period between 10 April and 30 April 2020. We identified 80 FTD consecutive cases, who were referred to the center during the calendar years 2018 and 2019 for diagnosis. Based on the study criteria, 33 patients were selected and all of them accepted to participate to the study. Overall, 32 telemedicine clinical interviews were completed. In one case, the encounter was not completed because the patient affected by bvFTD had died due to respiratory failure 3 months before the teleconsultation. Nearly all caregivers were patients' daughters/sons $(n=15)$ and spouses/partners $(n=15)$; one was a daughter-in-law and one a nephew. Finally, four interviews were also conducted directly with the patients. All patients included in the study lived at home. A video interaction was offered but refused by all patients because the large majority of participants did not own a computer or smartphone or, while they owned a cellphone, they were not familiar with this type of technology. All subjects contacted for the study felt comfortable during the interaction with the clinician. The total length of the telehealth visits was 60-90 minutes.

Demographic and clinical characteristics are summarized in Table 1. The patients include 18 males and 14 females (sex ratio $=1.3$ ) with mean age at evaluation of 66 years and mean duration of disease from onset of 73 months (Table 1). Clinical diagnoses were distributed as follow: 12 bvFTLD (39\%), 9 bvFTD plus Parkinsonism (28\%), 2 PPA (6\%), 3 PPA plus Parkinsonism (9\%), 2 bvFTD-PSP (6\%), 2 bvFTDMSA (6\%), and 2 bvFTD-ALS (6\%; Fig. 1). Among all domains explored during the telehealth evaluation, we found significant worsening since last visits mostly in behavior (56\%), language (47\%), and cog-

Table 1

Demographic and clinical features of FTD patients $(n=32)$

\begin{tabular}{lc}
\hline Sex M/F & $18 / 14$ \\
\hline Age at evaluation (mean \pm SD, y) & $66.25 \pm 9.76$ \\
$\begin{array}{l}\text { Disease duration since disease } \\
\text { onset (mean } \pm \text { SD, months) }\end{array}$ & $73.22 \pm 46.70$ \\
Time since last visit (mean \pm SD, months) & $6.78 \pm 3.84$ \\
Type diagnosis & \\
PPA & $\mathrm{N} 2$ \\
PPA-Parkinsonism & $\mathrm{N} 3$ \\
bvFTD & $\mathrm{N} 12$ \\
bvFTD-Parkinsonism & $\mathrm{N} 9$ \\
bvFTD-PSP & $\mathrm{N} 2$ \\
bvFTD-MSA & $\mathrm{N} 2$ \\
bvFTD-ALS & $\mathrm{N} 2$ \\
\hline
\end{tabular}




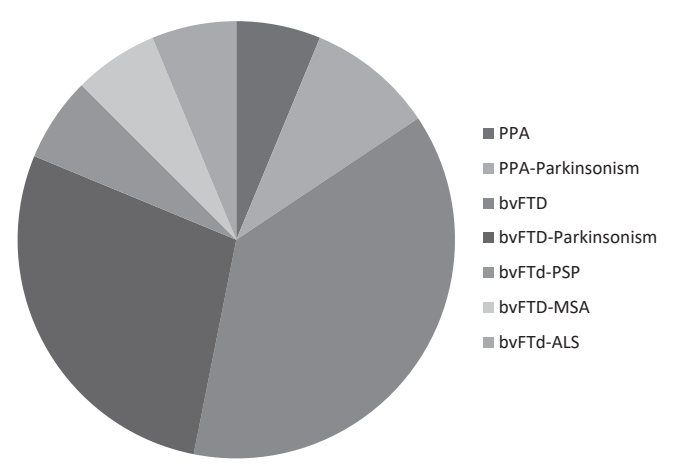

Fig. 1. Distribution of different FTD clinical phenotypes of patients enrolled in the teleconsultation. The clinical diagnoses of our cohort were distributed as follow: 12 bvFTD, 9 bvFTD plus Parkinsonism, 2 PPA, 3 PPA plus Parkinsonism, 2 bvFTD-PSP, 2 bvFTD-MSA, 2 bvFTD-ALS.

nitive functions (53\%; Fig. 2). Memory was described as worsened in 17 out 32 patients and ( 3 were patients with PPA (18\%) and 14 patients with bvFTD (82\%); Fig. 3). Significant sleep disturbances (problems in falling asleep, overall sleep quality) were reported in $25 \%$ of patients since the start of quarantine time (Fig. 2). All patients reporting sleep problems as disabling received new sleeping therapy prescriptions. Among all patients reporting the onset or worsening of preexisting behavior disorders, $78 \%$ of these were bvFTD and 22\% PPA (considering all the FTD spectrum together); while among all patients reporting the onset or worsening of preexisting language problems, $67 \%$ were bvFTD and 33\% PPA (Figs. 4 and 5). Nearly $30 \%$ of patients with the spectrum of bvFTD reported no changes since the last visits; 14 out 27 patients presented behavioral changes (apathy, irascibility, verbal aggressiveness, anger attacks), 7 out 27 patients presented with both language (anomia, reduced fluency) and behavior changes, 13 out 27 patients presented with both behavior and cognitive changes with prevalent memory disorders. All patients with PPA spectrum complained of a worsening of language functions since the last visit, in particular they reported more anomia and reduced verbal fluency. A significant worsening of behavior and language functions at CDR-FTD scale performed during teleconsultation compared to the CDR-FTD performed during last evaluation at the Center was reported ( $p=0.01$ and $p=0.009$, respectively); while, no differences were found for CDR SoB (Table 2).

In 8 out 32 patients (2 PPA plus parkinsonism, 6 bvFTD plus parkinsonism A), a mild worsening of bradykinesia and limb rigidity since last evaluation at the center was reported, while initial problems

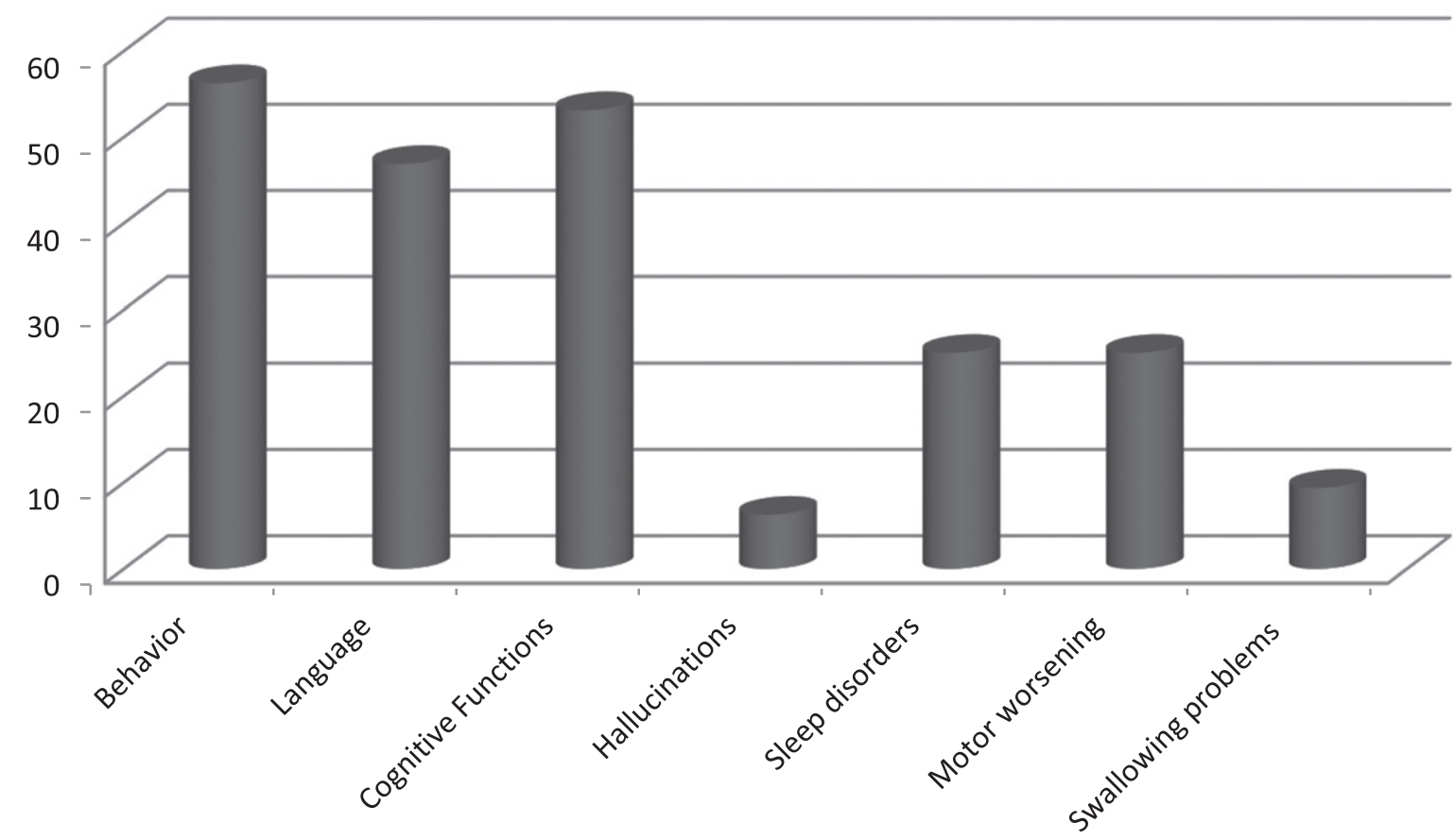

Fig. 2. Percentage of changes reported by patients/caregivers in the main domains investigate during multidisciplinary teleconsultation compared to last visit. During the telehealth evaluation, a significant worsening since last in person visit was observed mostly in behavior $(56 \%)$, language $(47 \%)$, and cognitive functions $(53 \%)$. 


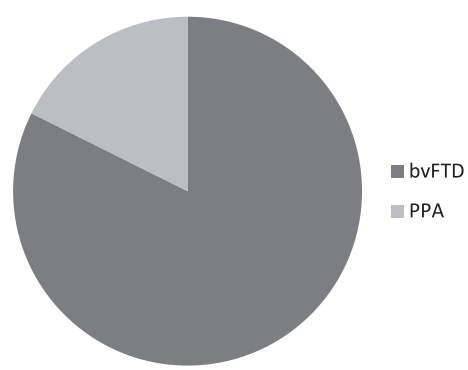

Fig. 3. Cognitive decline distribution among different behavioral and language clinical phenotypes. Memory was reported as worsened in 17 out 32 patients. Among these, 14 patients were affected bvFTD $(82 \%)$ and 3 were patients with PPA $(18 \%)$.

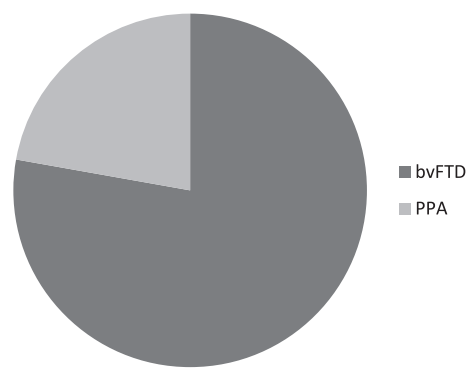

Fig. 4. Behavior worsening distribution among different behavioral and language clinical phenotypes. $78 \%$ of patients reporting the onset or worsening of preexisting behavior disorders were affected by bvFTD and $22 \%$ by PPA (considering all different bvFTD and PPA spectrum together); while among all patients reporting the onset or worsening of preexisting language problems, $67 \%$ were bvFTD and $33 \%$ PPA.

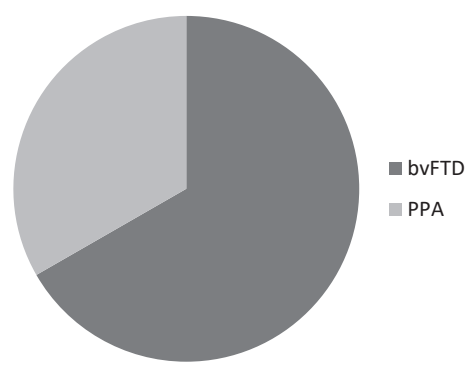

Fig. 5. Language worsening distribution among different behavioral and language clinical phenotypes. $67 \%$ of patients reporting the onset or worsening of preexisting language problems were affected by bvFTD and $33 \%$ by PPA.

Table 2

Functional evaluation of FTD patients enrolled in the teleconsultation by clinical Dementia Rating Scale-FTD

\begin{tabular}{lccc}
\hline & Last visit & Teleconsultation & $t$-test \\
\hline CDR SoB, mean \pm SD & $5.30 \pm 3.13$ & $5.41 \pm 3.11$ & 0.13 \\
CDR-Behavior & $1.41 \pm 0.70$ & $1.58 \pm 0.77$ & 0.01 \\
CDR-Language & $0.69 \pm 0.66$ & $0.86 \pm 0.79$ & 0.009 \\
\hline
\end{tabular}

Data are mean \pm SD.

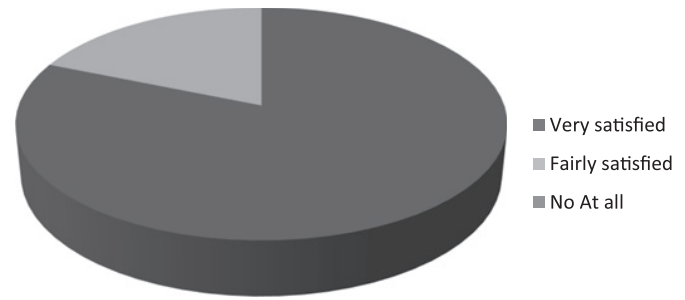

Fig. 6. Global level of satisfaction about the telehealth consultation of FTD spectrum patients/caregivers participating to the likingsurvey. Results from the satisfaction surveys indicated that most of the patients were consistently satisfied with the telemedicine visits $(88 \%)$. No patient was unsatisfied at all by the teleconsultation.

in swallowing was reported in 3 patients (1 bvPSP and 2 bvMSA). None of the patients enrolled in the study reported significant nutritional or respiratory changes, including the 2 patients with bvFTD-ALS.

With regards to treatment, the therapy was arbitrarily suspended in 3 patients by their caregivers and then promptly restored after the teleconsultation; only one patient with bvFTD-ALS reported that the therapy plan for riluzole was expired so it was renewed and then sent directly to the territorial pharmacy by email, in order to guarantee minimal exposure to virus infection of patients and their caregivers.

Sixteen patients with bvFTD associated with parkinsonian syndromes and all the 5 patients with PPA were performing physiotherapy and speech therapy at home before the outbreak and all of them reported a subjective feeling of discomfort after its discontinuation because of COVID-19 pandemic restrictions.

Based on the overall clinical information reported during the telehealth, a follow-up visit either in person or by telemedicine was ordered to be scheduled within three months for 26 out of the 32 patients.

All caregivers interviewed reported the presence of psychological and emotional distress; in particular 15 out $28(53 \%)$ reported a minimum or mild distress (1-2 on scale), while 13 out $28(47 \%)$ reported a moderate-severe distress (from 3 to 5 on scale).

Furthermore, we investigated the presence of any symptoms/signs potentially indicative of COVID19 infection (fever, cough, and other flu symptoms) in patients and in their caregivers. A patient with bvFTD-MSA was reported to present with fever and cough for a few days before the teleconsultation occurred on 10 April. A detailed epidemiological interview was reconstructed with the caregiver (the wife) who reported that the patient had been hospitalized until the beginning of March in a rehabilitation clinic in Lombardy in the Red Area of Italy (high 
Table 3

Survey's satisfaction and agreement level about telehealth experience

\begin{tabular}{|c|c|c|c|}
\hline & $\begin{array}{c}\text { Very } \\
\text { satisfied }\end{array}$ & $\begin{array}{l}\text { Fairly } \\
\text { satisfied }\end{array}$ & $\begin{array}{r}\text { Not at all } \\
\text { satisfied }\end{array}$ \\
\hline $\begin{array}{l}\text { Are you satisfied with the quality } \\
\text { of the voice sound during the } \\
\text { telehealth consultation? }\end{array}$ & $81 \%$ & $19 \%$ & $0 \%$ \\
\hline $\begin{array}{l}\text { Are you satisfied with the } \\
\text { Neurologist's skill to } \\
\text { understand your problems } \\
\text { during the telehealth } \\
\text { consultation? }\end{array}$ & $88 \%$ & $12 \%$ & $0 \%$ \\
\hline \multirow{2}{*}{$\begin{array}{l}\text { Globally, are you satisfied with } \\
\text { your experience with telehealth } \\
\text { consultation? }\end{array}$} & $81 \%$ & $19 \%$ & $0 \%$ \\
\hline & Yes & No & \\
\hline $\begin{array}{l}\text { Did you seem to be talking with } \\
\text { the Neurologist as you were } \\
\text { face-to-face with him? }\end{array}$ & $82 \%$ & $18 \%$ & \\
\hline $\begin{array}{l}\text { Did you feel comfortable during } \\
\text { the telehealth consultation? }\end{array}$ & $89.5 \%$ & $10.5 \%$ & \\
\hline $\begin{array}{l}\text { Did you think you have saved } \\
\text { money by avoiding travelling } \\
\text { to the center? }\end{array}$ & $88 \%$ & $12 \%$ & \\
\hline $\begin{array}{l}\text { Would you like to continue } \\
\text { follow-up also by telehealth } \\
\text { consultation in the future? }\end{array}$ & $90 \%$ & $10 \%$ & \\
\hline
\end{tabular}

prevalence of COVID-19 infection in the general population) during the COVID-19 pandemic. We contacted the family doctor of the patient who ordered an oropharyngeal swab that resulted positive for a COVID-19 infection. The patient did not need hospitalization and healed completely; furthermore, two consecutive swabs resulted negative for the infection in the following 2 weeks. None of his family members presented with COVID-19 symptoms/signs.

After a few days, 21 out of 32 subjects $(66 \%)$ participated in the satisfaction surveys. Most were consistently satisfied with the telemedicine visits (Fig. 6). In particular, they were satisfied with the clinical interview made by the neurologist (88\%), and by the possibility to interact directly and more easily with the clinician while being at home (88\%). The majority of subjects ( $88 \%$, Table 3 ) expressed their willingness to continue to be placed in the telemedicine program; they also underlined the cost reduction resulting from avoiding travel to the clinic, considering that more than $70 \%$ of the patients lived more than $30 \mathrm{~km}$ from the center.

\section{DISCUSSION}

The pandemic due to COVID-19 is changing clinical practice in neurology, after governments introduced social distancing, interrupting medical non-emergency services in many countries [38]. These decisions are particularly critical, in particular for elderly patients with chronic neurodegenerative diseases like dementias, because of the presence of physical frailty and comorbidities. To our knowledge, this is the first study that aimed to analyze the role of telemedicine as a valid tool to deliver and support care to people with FTD during the COVID-19 pandemic that placed Italy among the most seriously hit countries in the world. It is well known that dementia is a pandemic particularly relevant in consequent morbidity and mortality in Europe and North America, in countries with aging societies with high prevalence of elderly subjects [39]. The double hit of dementia and COVID-19 pandemics has generated great worries and issues for people with dementia and their families. All the issues are important for subjects at home and especially for people living in long-term residential care facilities, where the rate of spread and the reported mortality of COVID-19 were particularly high in all Europe [40].

Teleneurology is an effective tool for the rapid evaluation of patients in remote locations [17], with a well-established use in acute stroke $[18,19]$ and epilepsy [20, 21]. Telehealth is in the process of exponentially expanding as clinicians aim to preserve patients' access to clinical care during the COVID-19 pandemic [41].

Previous reports supported telemedicine as a useful tool for elderly patients with chronic illnesses such as dementias and their caregivers [42, 43]. In areas where there is inadequate presence and distribution of clinical resources and community health systems, telemedicine can improve access to specialists in tertiary centers, especially for patients who live in rural areas or have difficulties to reach the hospital [44]. Consistently, in a recent report the comparison of inperson and teletherapy revealed similar outcomes in treating PPA [45].

In the present study, at the peak of the COVID19 epidemic, we found that almost one out of two patients experienced a significant worsening of clinical picture and quality of life since the start of social distancing and quarantine time, due to behavioral changes and language and memory dysfunctions. We also identified in one out four patients sleep disturbances interfering with both patients and their caregivers' quality of daily life already compromised by forced cohabitation all day for the pandemic lockdown. Moreover, we observed an increase in the level of anxiety among caregivers at homes, under 
the dual stress of fear of infection and worries about the patients' condition, developing signs of exhaustion after about two months of full lockdown. Almost $50 \%$ of caregivers interviewed reported a moderatesevere emotional and psychological distress in the last period after the onset of the COVID-19 epidemic.

Notably, since we also performed a survey on possible COVID-19 symptoms, we identified one patient, reporting fever and cough after recently returning from Lombardy, an area with the highest prevalence of the epidemic. The patient did not need hospitalization and healed completely at home in the following 2 weeks. We wrote this report in the days immediately after the peak of COVID-19 in Italy with more than 200,000 cases and more than 30,000 deaths in the whole country on May 13 . The survey was conducted, however, in Puglia in the South-East of Italy, where the epidemic had much lower prevalence and mortality, compared to Lombardy and Veneto, NorthEast Italy. This study offers a great opportunity to underline to the patients and caregivers the rules and recommendations to prevent virus infection in subjects at high risk of infection with negative outcomes including death from COVID-19, as older adults with dementia and other underlying chronic health problems [39].

Telehealth is defined as "the use of electronic information and telecommunication technologies to support long-distance clinical healthcare, patient and professional health-related education, public health and health administration" [46]. People with prior known chronic neurologic diseases, including FTD, continue to need support and care even if not acutely ill. Telemedicine might be a well-suited instrument for ongoing management of such patients, particularly during a time when social distancing is encouraged [41, 47].

The use of an extensive and structured questionnaire assessing the main clinical domains in FTD and its administration by a specialist with a very high level of expertise in dementia are important strengths of the study. One of the main successes of our survey has been the prompt identification of a patient with COVID-19 hallmarks.

Strengths of our study are the relatively large number of participants, considering that FTD is a rare disease, the high response rate and the reallife recruitment of patients. Teleconsultation use also permitted us to bypass the limited Internet access for patients in a rural area. The area we surveyed is probably representative of a population with low web literacy and with limited use of new communication technologies. Indeed, all the patients/caregivers chose to interact via telephone or mail and refused video telemedicine because they did not have a smartphone and/or were not familiar with this type of technology. This points out that a social divide may be an important element to be considered when planning to implement advanced telemedicine systems [48]. Interestingly, all patients lived at home and none were in long-term residential facilities. This is probably linked to the characteristics of the system of social support in Southern Italy, still largely based on the family.

However, our study has some limitations, including: 1) the lack of opportunity for the telemedicine physician to perform both a physical and neurological examination; 2) the difficulties in the evaluation of some CDR-FTD subitems (as language assessment). The large majority of participants indeed did not own a computer or smartphone and we could not provide any specific support due to the outbreak restrictions. Future projects with telemedicine system and adequate devices (including video connection) would improve such assessments.

In conclusion, the COVID-19 pandemic has determined the preventive isolation of entire populations, disrupting the usual care of patients with chronic diseases. Unfortunately, Italy does not include telemedicine in the services granted by the National Health service [49]. Although no firm conclusions can be drawn given the observational design of our study, our findings with data collected during the peak of this pandemic seem to indicate that teleneurology is an effective tool for remote evaluation of patients with FTD, can serve as a safe and effective alternative to in-person care, and has a high level of satisfaction. The results of our study indeed showed a significant worsening of clinical feature and quality of life in half of patients with FTD and in a significant percentage of patients' caregivers.

Our study supports the use of telemedicine to better face both future epidemics and the usual care of complex patients. In our area, we are aiming with the project named Tecnopolo Puglia per la Medicina di Precisione to build upon an up-to-date telemedicine system with adequate devices to supply language rehabilitation [45].

\section{ACKNOWLEDGMENTS}

This work was supported by Regione Puglia (DGR n. 1284 - 27.05.2015) for the project "Registro 
Regionale per la SLA, la FTD-P e le patologie affini in Regione Puglia (SLAPDem registerwww.slapdem.it) and from Italian Ministry of Health (Ricerca Corrente) and Regione Puglia and CNR for Tecnopolo Puglia per la Medicina di Precisione (Tecnomed Puglia for Precision Medicine) D.G.R. n. 2117 of 21.11.2018.

Authors' disclosures available online (https:// www.j-alz.com/manuscript-disclosures/20-0589r1).

\section{SUPPLEMENTARY MATERIAL}

The supplementary material is available in the electronic version of this article: https://dx.doi.org/ 10.3233/JAD-200589.

\section{REFERENCES}

[1] Portnoy J, Waller M, Elliott T (2020) Telemedicine in the era of COVID-19. J Allergy Clin Immunol Pract 8, 1489-1491.

[2] Laforce R Jr. (2013) Behavioral and language variants of frontotemporal dementia: A review of key symptoms. Clin Neurol Neurosurg 115, 2405-2410.

[3] Shinagawa S (2013) Phenotypic variety in the presentation of frontotemporal lobar degeneration. Int Rev Psychiatry $\mathbf{2 5}$, 138-144.

[4] Hodges JR (2001) Frontotemporal dementia (Pick's disease): Clinical features and assessment. Neurology 56, S6-10.

[5] McKhann GM, Albert MS, Grossman M, Miller B, Dickson D, Trojanowski JQ (2001) Clinical and pathological diagnosis of frontotemporal dementia: Report of the Work Group on Frontotemporal Dementia and Pick's Disease. Arch Neurol 58, 1803-1809.

[6] Neary D, Snowden JS, Gustafson L, Passant U, Stuss D, Black S, Freedman M, Kertesz A, Robert PH, Albert M, Boone K, Miller BL, Cummings J, Benson DF (1998) Frontotemporal lobar degeneration: A consensus on clinical diagnostic criteria. Neurology 51, 1546-1554.

[7] Logroscino G, Piccininni M, Binetti G, Zecca C, Turrone R, Capozzo R, Tortelli R, Battista P, Bagoj E, Barone R, Fostinelli S, Benussi L, Ghidoni R, Padovani A, Cappa SF, Alberici A, Borroni B (2019) Incidence of frontotemporal lobar degeneration in Italy: The Salento-Brescia Registry study. Neurology 92, e2355-e2363.

[8] Kertesz A, Hillis A, Munoz DG (2003) Frontotemporal degeneration, Pick's disease, Pick complex, and Ravel. Ann Neurol 54(Suppl 5), S1-2.

[9] Ringholz GM, Appel SH, Bradshaw M, Cooke NA, Mosnik DM, Schulz PE (2005) Prevalence and patterns of cognitive impairment in sporadic ALS. Neurology 65, 586-590.

[10] Lomen-Hoerth C, Murphy J, Langmore S, Kramer JH, Olney RK, Miller B (2003) Are amyotrophic lateral sclerosis patients cognitively normal? Neurology 60, 10941097.

[11] Aoki N, Boyer PJ, Lund C, Lin WL, Koga S, Ross OA, Weiner M, Lipton A, Powers JM, White CL 3rd, Dickson DW (2015) Atypical multiple system atrophy is a new subtype of frontotemporal lobar degeneration: Frontotemporal lobar degeneration associated with alpha-synuclein. Acta Neuropathol 130, 93-105.

[12] Rankin KP, Kramer JH, Mychack P, Miller BL (2003) Double dissociation of social functioning in frontotemporal dementia. Neurology 60, 266-271.

[13] Grand JH, Caspar S, Macdonald SW (2011) Clinical features and multidisciplinary approaches to dementia care. $J$ Multidiscip Healthc 4, 125-147.

[14] Wylie MA, Shnall A, Onyike CU, Huey ED (2013) Management of frontotemporal dementia in mental health and multidisciplinary settings. Int Rev Psychiatry 25, 230-236.

[15] O'Connell ME, Crossley M, Cammer A, Morgan D, Allingham W, Cheavins B, Dalziel D, Lemire M, Mitchell S, Morgan E (2014) Development and evaluation of a telehealth videoconferenced support group for rural spouses of individuals diagnosed with atypical early-onset dementias. Dementia (London) 13, 382-395.

[16] https://www.epicentro.iss.it/coronavirus/pdf/sars-cov-2survey-rsa-rapporto-3.pdf

[17] Wechsler LR, Tsao JW, Levine SR, Swain-Eng RJ, Adams RJ, Demaerschalk BM, Hess DC, Moro E, Schwamm LH, Steffensen S, Stern BJ, Zuckerman SJ, Bhattacharya P, Davis LE, Yurkiewicz IR, Alphonso AL (2013) Teleneurology applications: Report of the Telemedicine Work Group of the American Academy of Neurology. Neurology 80, 670-676.

[18] Mutgi SA, Zha AM, Behrouz R (2015) Emerging subspecialties in neurology: Telestroke and teleneurology. Neurology 84, e191-193.

[19] Handschu R, Scibor M, Nuckel M, Asshoff D, Willaczek B, Erbguth F, Schwab S, Daumann F (2014) Teleneurology in stroke management: Costs of service in different organizational models. J Neurol 261, 2003-2008.

[20] Patterson V (2019) Managing epilepsy by telemedicine in resource-poor settings. Front Public Health 7, 321.

[21] Goldenholz DM, Moss R, Jost DA, Crone NE, Krauss G, Picard R, Caborni C, Cavazos JE, Hixson J, Loddenkemper T, Salazar TD, Lubbers L, Harte-Hargrove LC, Whittemore V, Duun-Henriksen J, Dolan E, Kasturia N, Oberemk M, Cook MJ, Lehmkuhle M, Sperling MR, Shafer PO (2018) Common data elements for epilepsy mobile health systems. Epilepsia 59, 1020-1026.

[22] Tsanas A, Little MA, McSharry PE, Ramig LO (2010) Accurate telemonitoring of Parkinson's disease progression by noninvasive speech tests. IEEE Trans Biomed Eng 57, 884-893.

[23] Bossen AL, Kim H, Williams KN, Steinhoff AE, Strieker M (2015) Emerging roles for telemedicine and smart technologies in dementia care. Smart Homecare Technol Telehealth 3, 49-57.

[24] Hollander JE, Carr BG (2020) Virtually perfect? Telemedicine for Covid-19. N Engl J Med 382, 1679-1681.

[25] Kim H, Jhoo JH, Jang JW (2017) The effect of telemedicine on cognitive decline in patients with dementia. $J$ Telemed Telecare 23, 149-154.

[26] Lindauer A, Seelye A, Lyons B, Dodge HH, Mattek N, Mincks K, Kaye J, Erten-Lyons D (2017) Dementia care comes home: Patient and caregiver assessment via telemedicine. Gerontologist 57, e85-e93.

[27] Loh PK, Donaldson M, Flicker L, Maher S, Goldswain P (2007) Development of a telemedicine protocol for the diagnosis of Alzheimer's disease. J Telemed Telecare 13, 90-94.

[28] Cotelli M, Manenti R, Brambilla M, Gobbi E, Ferrari C, Binetti G, Cappa SF (2019) Cognitive telerehabilita- 
tion in mild cognitive impairment, Alzheimer's disease and frontotemporal dementia: A systematic review. $J$ Telemed Telecare 25, 67-79.

[29] (2020) Alzheimer's disease research enterprise in the era of COVID-19/SARS-CoV-2. Alzheimers Dement 16, 587-588.

[30] Rascovsky K, Hodges JR, Knopman D, Mendez MF, Kramer JH, Neuhaus J, van Swieten JC, Seelaar H, Dopper EG, Onyike CU, Hillis AE, Josephs KA, Boeve BF, Kertesz A, Seeley WW, Rankin KP, Johnson JK, Gorno-Tempini ML, Rosen H, Prioleau-Latham CE, Lee A, Kipps CM, Lillo P, Piguet O, Rohrer JD, Rossor MN, Warren JD, Fox NC, Galasko D, Salmon DP, Black SE, Mesulam M, Weintraub S, Dickerson BC, Diehl-Schmid J, Pasquier F, Deramecourt V, Lebert F, Pijnenburg Y, Chow TW, Manes F, Grafman J, Cappa SF, Freedman M, Grossman M, Miller BL (2011) Sensitivity of revised diagnostic criteria for the behavioural variant of frontotemporal dementia. Brain 134, 2456-2477.

[31] Gorno-Tempini ML, Hillis AE, Weintraub S, Kertesz A, Mendez M, Cappa SF, Ogar JM, Rohrer JD, Black S, Boeve BF, Manes F, Dronkers NF, Vandenberghe R, Rascovsky K, Patterson K, Miller BL, Knopman DS, Hodges JR, Mesulam MM, Grossman M (2011) Classification of primary progressive aphasia and its variants. Neurology 76, 1006-1014.

[32] Boxer AL, Yu JT, Golbe LI, Litvan I, Lang AE, Hoglinger GU (2017) Advances in progressive supranuclear palsy: New diagnostic criteria, biomarkers, and therapeutic approaches. Lancet Neurol 16, 552-563.

[33] Armstrong MJ, Litvan I, Lang AE, Bak TH, Bhatia KP, Borroni B, Boxer AL, Dickson DW, Grossman M, Hallett M, Josephs KA, Kertesz A, Lee SE, Miller BL, Reich SG, Riley DE, Tolosa E, Troster AI, Vidailhet M, Weiner WJ (2013) Criteria for the diagnosis of corticobasal degeneration. $\mathrm{Neu}$ rology 80, 496-503.

[34] Palma JA, Norcliffe-Kaufmann L, Kaufmann H (2018) Diagnosis of multiple system atrophy. Auton Neurosci 211, 15-25.

[35] Strong MJ, Abrahams S, Goldstein LH, Woolley S, McLaughlin P, Snowden J, Mioshi E, Roberts-South A, Benatar M, HortobaGyi T, Rosenfeld J, Silani V, Ince PG, Turner MR (2017) Amyotrophic lateral sclerosis frontotemporal spectrum disorder (ALS-FTSD): Revised diagnostic criteria. Amyotroph Lateral Scler Frontotemporal Degener 18, 153-174.

[36] Mioshi E, Flanagan E, Knopman D (2017) Detecting clinical change with the CDR-FTLD: Differences between FTLD and AD dementia. Int J Geriatr Psychiatry 32, 977-982.

[37] Cummings JL, Mega M, Gray K, Rosenberg-Thompson S, Carusi DA, Gornbein J (1994) The Neuropsychiatric Inventory: Comprehensive assessment of psychopathology in dementia. Neurology 44, 2308-2314.
[38] Bloem BR, Dorsey ER, Okun MS (2020) The coronavirus disease 2019 crisis as catalyst for telemedicine for chronic neurological disorders. JAMA Neurol, doi: 10.1001/jamaneurol.2020.1452

[39] Wang H, Li T, Barbarino P, Gauthier S, Brodaty H, Molinuevo JL, Xie H, Sun Y, Yu E, Tang Y, Weidner W, Yu $X$ (2020) Dementia care during COVID-19. Lancet 395, $1190-1191$.

[40] Notarnicola E, https://www.corriere.it/esteri/20_aprile_23/ coronavirus-strage-rsa-sette-cose-che-non-hanno-funziona to-8f5864c6-8594-11ea-b71d-7609e1287c32.shtml, Accessed April 17, 2020.

[41] Nijeweme-d'Hollosy WO, Janssen EP, Huis in 't Veld RM, Spoelstra J, Vollenbroek-Hutten MM, Hermens HJ (2006) Tele-treatment of patients with amyotrophic lateral sclerosis (ALS). J Telemed Telecare 12(Suppl 1), 31-34.

[42] Cheong CK, Lim KH, Jang JW, Jhoo JH (2015) The effect of telemedicine on the duration of treatment in dementia patients. J Telemed Telecare 21, 214-218.

[43] Botsis T, Hartvigsen G (2008) Current status and future perspectives in telecare for elderly people suffering from chronic diseases. J Telemed Telecare 14, 195-203.

[44] Barton C, Morris R, Rothlind J, Yaffe K (2011) Videotelemedicine in a memory disorders clinic: Evaluation and management of rural elders with cognitive impairment. Telemed J E Health 17, 789-793.

[45] Dial HR, Hinshelwood HA, Grasso SM, Hubbard HI, Gorno-Tempini ML, Henry ML (2019) Investigating the utility of teletherapy in individuals with primary progressive aphasia. Clin Interv Aging 14, 453-471.

[46] HealthIT.gov. Telemedicine and telehealth, https://www. healthit.gov/topic/health-it-initiatives/telemedicine-and-tel ehealth. Accessed March 24, 2020.

[47] Brown EE, Kumar S, Rajji TK, Pollock BG, Mulsant BH (2020) Anticipating and mitigating the impact of the COVID-19 pandemic on Alzheimer's disease and related dementias. Am J Geriatr Psychiatry, doi: 10.1016/j.jagp.2020.04.010

[48] Walker DM, Hefner JL, Fareed N, Huerta TR, McAlearney AS (2020) Exploring the digital divide: Age and race disparities in use of an inpatient portal. Telemed J E Health 26, 603-613.

[49] Ohannessian R, Duong TA, Odone A (2020) Global telemedicine implementation and integration within health systems to fight the COVID-19 pandemic: A call to action. JMIR Public Health Surveill 6, e18810. 